\title{
BfpU, a soluble protein essential for type IV pilus biogenesis in enteropathogenic Escherichia coli
}

\author{
Wiebke Schreiber, ${ }^{1} \dagger$ Kelly D. Stone, ${ }^{1} \dagger$ Margaret A. Strong, ${ }^{2}$ \\ Louis J. DeTolla, Jr, ${ }^{2}$ Michael Hoppert ${ }^{3}$ and Michael S. Donnenberg ${ }^{1}$
}
1,2 Molecular and Cellular Biology Program, Division of Infectious Diseases ${ }^{1}$ and Comparative Medicine Program, Department of Medicine, 2 University of Maryland, Baltimore, School of Medicine, Baltimore, MD 21201, USA
3 Institut für Mikrobiologie und Genetik, Georg- August Universität, Grisebachstrasse 8, 37077 Göttingen, Germany

\author{
Author for correspondence: Michael S. Donnenberg. Tel: +1 410706 7560. Fax: +1 4107068700. \\ e-mail:mdonnenb@umaryland.edu
}

\begin{abstract}
A cluster of 14 genes located on the large plasmid of enteropathogenic Escherichia coli (EPEC) strains is sufficient to direct the biogenesis of the type IV bundle-forming pilus (BFP) in a recombinant $E$. coli host. The fifth gene in the cluster, bfpU, encodes a protein that is predicted to be localized to the periplasmic space. To determine whether $\mathrm{BfpU}$ is necessary for pilus biogenesis, the authors constructed a non-polar bfpU mutant EPEC strain by allelic exchange. The mutant strain was unable to perform localized adherence and auto-aggregation, two phenotypes associated with BFP expression, and it failed to make BFP. These phenotypes were restored to the bfpU mutant by a plasmid containing bfpU. There was no difference between the wild-type and bfpU mutant strains in their expression or processing of the pre-pilin protein or in their localization of the pilin protein in the inner and outer membranes. Fractionation studies revealed that $\mathrm{BfpU}$ is completely soluble and is detected in both the periplasm and the cytoplasm. Thus, BfpU represents a novel protein required for type IV pilus assembly.
\end{abstract}

Keywords: type IV fimbriae, periplasm, bundle-forming pili, bundlin

\section{INTRODUCTION}

Type IV pili are produced by many Gram-negative bacteria of medical and veterinary importance. The biogenesis of type IV pili appears to be quite complex, but is poorly understood. The isolation and characterization of mutants that are deficient in type IV pilus production, or in phenotypes associated with the production of these fimbriae, has provided much useful information. More than 30 genes required for the expression of functional type IV pili have been described in Pseudomonas aeruginosa (Alm \& Mattick, 1997).

Despite the identification of many genetic loci that are required for type IV pilus expression, little insight has been gained into the process of type IV pilus morphogenesis. The functions of only three of the proteins involved in this process are well understood. The pilin protein itself has been studied in detail. This protein

†These authors contributed equally to this paper.

Abbreviations: BFP, bundle-forming pilus/pili; EPEC, enteropathogenic Escherichia coli. makes up most, if not all, of the subunits of the pilus, where it is arranged in a helical array (Paranchych \& Frost, 1988). The pilin proteins of several bacterial species are known to be modified by glycosylation and/or phosphorylation (Virji et al., 1993; Stimson et al., 1995; Castric, 1995; Forest et al., 1999). The crystal structure of the complete pilin from Neisseria gonorrhoeae has been solved and has been shown to resemble a ladle, with a long, amino-terminal handle composed of an uninterrupted hydrophobic $\alpha$-helix and a head composed predominantly of anti-parallel $\beta$-sheets (Parge et al., 1995). It is postulated that the handles form the core of the pilus, while certain antigenic regions of the rest of the protein protrude from the pilus surface. According to a theoretical model of bundlin (Protein Database accession no. 1QT2; http://www.rcsb.org/ $\mathrm{pdb} /$ ), the type IV pilin of enteropathogenic Escherichia coli (EPEC), highly variable amino acids of bundlin from different EPEC strains are also predominantly located on the surface (Blank et al., 2000). The pre-pilin peptidase is another type IV pilus biogenesis protein that is well understood. In P. aeruginosa this protein is a bifunctional cytoplasmic transmembrane protein which cleaves off the short, hydrophilic pre-pilin signal se- 
Table 1. E. coli strains and plasmids used in this study

\begin{tabular}{|c|c|c|}
\hline Strain/plasmid & Description/genotype & Reference/source \\
\hline \multicolumn{3}{|l|}{ Strains } \\
\hline BL21(DE3) & E. coli $\mathrm{B} \mathrm{F}^{-} d c m$ ompT hsdS $\left(\mathrm{r}_{\mathrm{B}}^{-} \mathrm{m}_{\mathrm{B}}^{-}\right)$gal ( $\left.\lambda \mathrm{DE} 3\right)$ & Stratagene \\
\hline $\mathrm{DH} 5 \alpha$ & $\begin{array}{l}\text { deoR endA1 gyrA96 hsdR17 recA1 relA1 supE44 thi-1 } \Delta(\text { lacIZYA-argF)U169 } \\
\text { (\$80lacZ } \Delta \text { M15) }\end{array}$ & Gibco-BRL \\
\hline DH5 $\alpha \lambda$ pir & $\mathrm{DH} 5 \alpha(\lambda p i r)$ & Ménard et al. (1993) \\
\hline $\mathrm{E} 2348 / 69$ & Serotype O127:H6 EPEC strain isolated from an outbreak in the UK & Levine et al. (1978) \\
\hline JPN15 & E2348/68 cured of the large plasmid encoding the $b f p$ cluster & Levine et al. (1985) \\
\hline M15 & $\mathrm{Lac}^{-} \mathrm{Ara}^{-} \mathrm{Gal}^{-} \mathrm{Mtl}^{-} \mathrm{F}^{-}$ & Qiagen \\
\hline UMD901 & $\mathrm{E} 2348 / 69$ bfpA C129S & Zhang \& Donnenberg (1996) \\
\hline UMD922 & $\mathrm{E} 2348 / 69 \Delta b f p U 1:: a p h A-3$ & This study \\
\hline \multicolumn{3}{|l|}{ Plasmids } \\
\hline pBluescript & High-copy-number cloning vector & Stratagene \\
\hline pBR322 & Low-copy-number cloning vector & Gibco-BRL \\
\hline pCR-Script & Derivative of pBluescript for cloning PCR products & Stratagene \\
\hline pCVD442 & pir-dependent, $s a c B$-containing suicide vector & Donnenberg \& Kaper (1991) \\
\hline pKDS135 & $B f p A-L$ cloned in $\mathrm{p} \operatorname{Trc} 99 \mathrm{~A}$ & Stone et al. (1996) \\
\hline pKDS5.1 & $2 \cdot 1 \mathrm{~kb}$ EagI-Pst I fragment containing $b f p U$ cloned in pBluescript & This study \\
\hline pKDS5.2(3') & PCR product using primers Donne- 199 and Donne- 12 cloned in pCR-Script & This study \\
\hline $\mathrm{pKDS} 5.2\left(5^{\prime}\right)$ & PCR product using primers Donne-198 and Donne- 33 cloned in pCR-Script & This study \\
\hline pKDS5.3 & SmaI-PstI fragment of pKDS5.2(3') cloned into pKDS5.2(5') & This study \\
\hline pKDS5.4 & SmaI fragment of pUC18K2 cloned into pKDS5.3 & This study \\
\hline pKDS5.5 & $3 \cdot 3 \mathrm{~kb}$ SalI fragment of pKDS5.4 cloned into pCVD442 & This study \\
\hline pKDS5.30H & PCR product using primers Donne- 121 and Donne- 122 cloned in pQE30 & This study \\
\hline pMSD201 & $5 \cdot 3 \mathrm{~kb}$ Bam HI fragment containing $b f p A-D^{\prime}$ cloned in pBR322 & Donnenberg et al. (1992) \\
\hline pMSD205 & $b f p A$ gene cloned in pCR1000 (Qiagen) & Donnenberg et al. (1992) \\
\hline pMSD232 & $\begin{array}{l}\text { bfpU gene amplified with primers Donne- } 122 \text { and Donne- } 234 \text { cloned into } \\
\text { pWKS30 }\end{array}$ & This study \\
\hline pMSD233 & $5 \cdot 3 \mathrm{~kb} B a m \mathrm{HI}$ fragment containing $b f p A-D^{\prime}$ cloned in $\mathrm{pWKS} 30$ & Anantha et al. (2000) \\
\hline pMSD234 & PCR product using primers Donne-234 and Donne- 274 cloned in pCR-Script & This study \\
\hline pMSD235 & $\begin{array}{l}X b a \mathrm{I}-\mathrm{SacII} \text { fragment of pMSD } 234 \text { containing } b f p U \text { with additional six His } \\
\text { codons at the } 3^{\prime} \text { end cloned in pRPA103 }\end{array}$ & This study \\
\hline pQE30 & Expression vector for producing amino-terminal hexahistidine fusion proteins & Qiagen \\
\hline pREP4 & Plasmid containing lacI gene for repression of lac promoter & Qiagen \\
\hline pRPA103 & $4 \cdot 3 \mathrm{~kb} B a m \mathrm{HI}-X b a \mathrm{I}$ fragment containing $b f p A-b f p U^{\prime}$ cloned in pWKS30 & Anantha et al. (2000) \\
\hline pTrc99A & pBR322 derivative with $\operatorname{trc}$ promoter & Amersham Pharmacia Biotech \\
\hline pUC18K2 & $\begin{array}{l}\text { Derivative of pUC18K (Ménard et al., 1993) with additional G residue after } \\
\text { ATG start }\end{array}$ & $\begin{array}{l}\text { K. Jarvis \& J. Kaper } \\
\text { (unpublished) }\end{array}$ \\
\hline pWKS30 & Low-copy-number cloning vector & Wang \& Kushner (1991) \\
\hline
\end{tabular}

quence and $N$-methylates the new amino terminus of the pilin (Strom et al., 1993). Pre-pilin peptidases compose a unique class of bi-lobed aspartate proteases (LaPointe $\&$ Taylor, 2000). A third protein, the secretin, has been analysed in some detail in the $P$. aeruginosa type IV pilus system and also in EPEC. This outer-membrane protein forms multimeric ring-shaped structures that are postulated to allow the passage of intact pili through the outer membrane (Bitter et al., 1998; Schmidt et al., 2001; Wolfgang et al., 2000).

Mutants defective in the production of type IV pili with disruptions in numerous other genes have been described, but analyses of these mutants have shed little light on the process of type IV pilus biogenesis. A principal reason for this lack of illumination is that these mutants all have similar phenotypes. In most cases, the pre-pilin protein is produced and processed, no pili are made and fractionation studies reveal that the pilin copurifies with membrane components (Nunn et al., 1990; Alm \& Mattick, 1995; Alm et al., 1996a, b; Anantha et al., 2000). In striking contrast to chaperone-usher pilus biogenesis systems, best exemplified by $\mathrm{P}$ fimbriae, no periplasmic phase of export has been described for type IV pilus biogenesis. Thus, no mutations of type IV pilus biogenesis genes have resulted in the accumulation of free pilin in the periplasmic space and no periplasmic chaperones have been described. This has led some 
investigators to propose models for type IV pilus biogenesis that include no periplasmic phase of export, but instead envisage a structure that spans the inner and outer membranes (Fussenegger et al., 1997; Iredell \& Manning, 1994; Hobbs \& Mattick, 1993). Recently, the use of conditional double-knockout mutants has allowed the dissection of type IV pilus formation into three different phases - pilin processing, pilus formation and pilus extrusion (Wolfgang et al., 1998, 2000). To reveal these phases, it was essential to inactivate PilT, a putative ATP-binding protein involved in pilus retraction (Merz et al., 2000). This protein seems to act in quality control by preventing fibre formation and, in turn, minimizing growth defects that may occur in the absence of essential biogenesis components.

Another striking feature of type IV pilus biogenesis systems is their similarity to type II secretion systems (Pugsley, 1993; Hobbs \& Mattick, 1993; Russel, 1998; Nouwen et al., 1999, 2000). Type II secretion systems are responsible for the export of a variety of extracellular toxins and enzymes through the outer membrane. These exported proteins are first secreted into the periplasmic space by the Sec translocation system. Among the components shared between type IV pilus and type II secretion systems are a polytopic cytoplasmic transmembrane protein, a cytoplasmic nucleotide-binding protein, an outer-membrane secretin, a pre-pilin peptidase and several pre-pilin peptidase substrates. This extensive conservation of components implies that the two systems share common mechanisms.

We, and others, have previously described a cluster of 14 bfp genes from EPEC that is associated with the production of the type IV bundle-forming pilus (BFP) of this organism (Stone et al., 1996; Sohel et al., 1996). When cloned into a laboratory strain of E. coli and placed under the control of an artificial promoter, these 14 genes are sufficient to direct the synthesis of the BFP. Thus, the BFP system is an excellent model for the study of type IV pilus biogenesis, since all of the required components are known. Four of the 14 genes of the $b f p$ cluster have no known homologues in other type IV pilus systems. One of the most intriguing of these four genes is $b f p U$, which is predicted to encode a $17 \mathrm{kDa}$ protein that has a typical type I signal peptidase cleavage site (Stone et al., 1996). As the rest of the protein is predicted to be hydrophilic, it seems likely that BfpU resides in the periplasmic space. Thus, we decided to test the hypothesis that $b f p U$ encodes a periplasmic protein required for type IV pilus biogenesis.

\section{METHODS}

Strains, plasmids and culture conditions. The bacterial strains and plasmids used in this study are listed in Table 1 . Unless indicated, all bacterial strains were grown on LB agar plates at $37^{\circ} \mathrm{C}$ or in LB broth at $37^{\circ} \mathrm{C}$ with aeration. Antibiotics were added as needed at the following concentrations: $200 \mu \mathrm{g}$ ampicillin $\mathrm{ml}^{-1} ; 20 \mu \mathrm{g}$ chloramphenicol $\mathrm{ml}^{-1} ; 50 \mu \mathrm{g}$ kanamycin $\mathrm{ml}^{-1} ; 30 \mu \mathrm{g}$ tetracycline $\mathrm{ml}^{-1}$. To induce BFP expression, overnight LB cultures were diluted 1:50 in $20 \mathrm{ml}$ Dulbecco's modified Eagle's medium (DMEM) in $50 \mathrm{ml}$ conical tubes. The cultures were incubated at $37{ }^{\circ} \mathrm{C}$ with shaking (250 r.p.m.) for 4-6 h until the $\mathrm{OD}_{600}$ reached approximately $0 \cdot 5$, at which time visible aggregates were apparent in cultures of wild-type organisms.

HEp-2 cells were maintained in Eagle's minimal essential media (EMEM) supplemented with $10 \%$ foetal bovine serum, $100 \mu \mathrm{g}$ streptomycin $\mathrm{ml}^{-1}$ and $100 \mathrm{U}$ penicillin ml $\mathrm{ml}^{-1}$ at $37^{\circ} \mathrm{C}$ with $5 \% \mathrm{CO}_{2}$.

Construction of a bfpU mutant. A fragment of the $b f p$ gene cluster (GenBank accession no. Z68186; Donnenberg et al., 1992; Stone et al., 1996) extending from nucleotide 3586 to 4350 and containing an XmaI site at its $3^{\prime}$ end was amplified from plasmid pKDS5.1 using primers Donne-198 and the T7 primer from the pBluescript vector. Similarly, a fragment extending from nucleotide 4560 to 5702 of the $b f p$ gene cluster and containing an XmaI site at its $5^{\prime}$ end was amplified using primer Donne-199 and the universal reverse primer. These fragments were cloned separately into pCR-Script and then joined by their XmaI sites, to produce pKDS5.3. The aphA-3 kanamycin-resistance cassette was cloned from pUC18K2 into the XmaI site of pKDS5.3, to produce pKDS5.4. The $3.3 \mathrm{~kb}$ SalI fragment from pKDS5.4 was cloned into positive-selection suicide vector pCVD442 to create pKDS5.5. Allelic exchange was performed as described previously (Donnenberg et al., 1993). PCR was performed using primer pairs Donne28/Donne-29, Donne-110/Donne-111 and Donne-121/ Donne-122, to verify the size of the $b f p A, b f p I$ and $b f p U$ genes, respectively. Details for all of the Donne- primers used in this study can be found in Table 2 .

Generation and purification of fusion proteins. We amplified a fragment of $b f p U$ using primers Donne-121 and Donne-122, which were designed to delete the codons for the first 18 aa of the pre-protein. The product of this PCR was cloned into pQE30 to produce pKDS5.30H, which encodes an aminoterminal hexahistidine-BfpU fusion protein. Using primers Donne-234 and Donne-274, we also amplified a fragment that contained $b f p U$ with six His codons added at the $3^{\prime}$ end. Cloning of this fragment into pCR-Script produced pMSD234. Replacing the XbaI-SacII fragment of pRPA103 with that of pMSD234 resulted in the production of pMSD235. Strain M15 carrying pREP4 and pKDS5.30H and mutant strain UMD922 complemented with pMSD325 were used to produce the respective fusion proteins. BfpU was purified on a nickel/ nitriloacetic acid column under native conditions, following the guidelines of the manufacturer (Qiagen). Hexahistidinetagged pre-bundlin was purified as described previously (Zhang \& Donnenberg, 1996).

Antibody production. The purified $\mathrm{N}$-terminal hexahistidinetagged BfpU was used for the production of $\mathrm{mAbs}$ in BALB/c mice using standard procedures. Ascites was prepared commercially (BioWorld, Dublin, $\mathrm{OH}$ ) and purified using an E-Z Sep kit (Amersham Pharmacia Biotech), according to the manufacturer's instructions. Mouse polyclonal anti-BfpU serum was obtained at the same time as spleen cells were harvested for production of the mAbs and absorbed against an acetone powder prepared from the $b f p U$ mutant. All procedures were part of a protocol approved by the IACUC of the University of Maryland, School of Medicine. Animals were housed in a facility accredited by the Association for Accreditation and Assessment of Laboratory Animal Care (AAALAC), International, and directed by a board-certified Laboratory Animal Veterinarian. 
Table 2. Oligonucleotides used in this study

\begin{tabular}{|c|c|c|}
\hline Primer & Sequence $\left(5^{\prime} \rightarrow 3^{\prime}\right)^{*}$ & Purpose \\
\hline Donne-12 & AACAGCTATGACCATG & $\begin{array}{l}\text { Universal reverse; (with Donne-199) to amplify 3' } \\
\text { end of } b f p U\end{array}$ \\
\hline Donne-28 & CGCGGATCCATGGTTTCTAAAATCATGAAT & $5^{\prime}$ End of $b f p A$ \\
\hline Donne-29 & GCGAAGCTTTTACTTCATAAAATATGTAAC & $3^{\prime}$ End of $b f p A$ \\
\hline Donne-37 & TAATACGACTCACTATAGGG & T7; (with Donne-198) to amplify $5^{\prime}$ end of $b f p U$ \\
\hline Donne-110 & GGCGGGATCCGTAAGTAAAAATTATGGTTCG & $5^{\prime}$ End of $b f p I$ \\
\hline Donne-111 & GCCGAAGCTTAAAGGCCGCTTTCTTTTC & $3^{\prime}$ End of $b f p I$ \\
\hline Donne-121 & CGCGGATCCGAGGTCAATACAAGTGTTG & Nucleotides $55-73$ of $b f p U$ \\
\hline Donne-122 & GCGAAGCTTCTATCTCAGAAAAATTTTCTGCACGGG & $3^{\prime}$ End of $b f p U$ \\
\hline Donne-198 & GGCGCCCGGGCGCTGAAGTTCCTGATAGG & Complementary to nucleotides $158-176$ of $b f p U$ \\
\hline Donne-199 & GGCGCCCGGGGGTGAGCGACATTACCGG & Nucleotides $387-403$ of $b f p U$ \\
\hline Donne-234 & GTCGACGGGGAGTGCTTAGTTTG & $5^{\prime}$ End of $b f p U$ \\
\hline Donne-274 & $\begin{array}{l}\text { CCGCGGCTAGTGATGGTGATGGTGATGCCCTCTCAG- } \\
\text { AAAAATTTTCT }\end{array}$ & $3^{\prime}$ End of $b f p U$ (plus codons for six His) \\
\hline Donne-300 & GGATCCGGGGAGAGCTTAGTATTGAAAAAAATATTG & $5^{\prime}$ End of $b f p U$ with ATG start codon \\
\hline
\end{tabular}

*Bold nucleotides indicate restriction endonuclease sites introduced for cloning. The bold underlined nucleotide indicates the substitution of $\mathrm{A}$ for $\mathrm{T}$ to enhance expression.

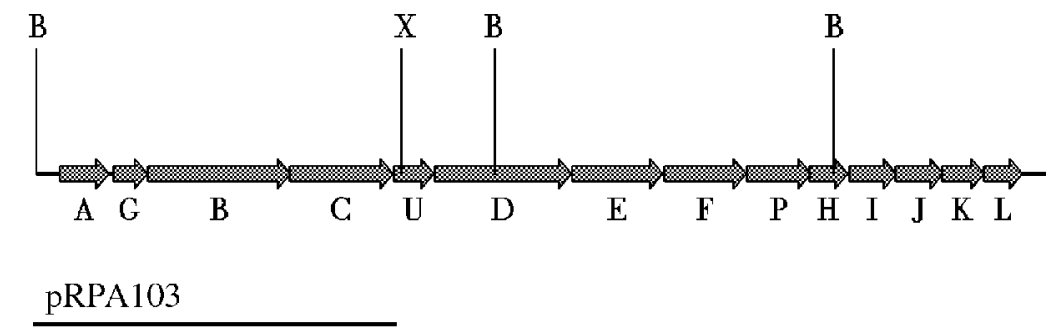

\begin{abstract}
Fig. 1. Schematic of the bfp gene cluster showing the localization of bfpU. Relevant restriction sites are shown above the genes (B: BamHI, X: Xbal). The lines beneath the genes represent the fragment used for successful complementation (MSD233) and the control plasmid ending within bfpU (RPA103).
\end{abstract}

pMSD233

Localized adherence and auto-aggregation assays. Assays for localized adherence to HEp-2 cells and for auto-aggregation were performed as described previously (Donnenberg \& Nataro, 1995; Anantha et al., 1998).

Immunoblotting. Proteins were separated by SDS-PAGE and transferred to PVDF membranes by the method of Towbin et al. (1979). Primary antibodies were used at the following dilutions: anti-BfpU mAb 8C8, 1:60000; polyclonal antibundlin (Zhang \& Donnenberg, 1996), 1:5000; monoclonal anti-bundlin ICA4 (Girón et al., 1995), 1:30000; anti-maltosebinding protein (New England Biolabs), 1:10000; anti- $\beta$ galactosidase $\left(5^{\prime}\right.$ to $3^{\prime}$; Boulder, CO), 1:1000; anti-penicillinbinding protein 1B (a gift of Nanne Nanninga, University of Amsterdam), 1:2000; anti-intimin (Jerse \& Kaper, 1991), $1: 1000$. Secondary goat-anti-mouse IgG or goat-anti-rabbit IgG antiserum conjugated to horseradish peroxidase (Amersham Pharmacia Biotech) was used at a dilution of $1: 30000$. Blots were developed by enhanced chemiluminescence (Amersham Pharmacia Biotech). When necessary, blots were stripped according to the manufacturer's instructions.

For quantitative immunoblotting, protein concentrations of a whole-cell lysate of wild-type EPEC strain E2348/69 grown under BFP-expressing conditions and of purified His-tagged proteins were determined using a bicinchoninic acid assay (Pierce). Prior to cell lysis, the c.f.u. count for the wild-type culture was determined by plating out serial dilutions of the culture and enumerating the number of colonies formed. Samples with a range of protein concentrations were separated by $15 \%$ SDS-PAGE and analysed by immunoblotting, as described above. The blots were scanned on a Hewlett Packard ScanJet $4 \mathrm{c}$ machine and analysed using Scion Image software (Scion). Standard curves of relative intensity versus the logarithm of the number of molecules of His-tagged proteins present were generated using Microsoft Excel. The correlation coefficients of these curves were $>0 \cdot 95$. From these curves, the number of molecules of bundlin and BfpU in the whole-cell preparations was calculated and the relative amounts of these proteins were determined.

Electron microscopy. For negative-staining of BFP, bacteria were grown and prepared as described previously (Anantha et al., 2000). Cells used in the immunolocalization experiments were grown in DMEM until visible aggregation occurred. For plasmolysis, the cells were harvested by centrifugation, resuspended in $1 / 10 \mathrm{vol}$. of an ice-cold sucrose solution $(0 \cdot 3 \mathrm{M}$ sucrose, $0 \cdot 15 \mathrm{M}$ Tris) and incubated on ice for $30 \mathrm{~min}$. After 
adding 10 vols of an EDTA solution $(0 \cdot 1 \mathrm{M}, \mathrm{pH} 8)$, the cells were collected by centrifugation and washed twice. They were then chemically fixed (at $4{ }^{\circ} \mathrm{C}$ for at least $1 \mathrm{~h}$ ) in PBS $(10 \mathrm{mM}$ sodium phosphate, $137 \mathrm{mM}$ sodium chloride, $\mathrm{pH} 7 \cdot 0$ ) with $0.2 \%(\mathrm{w} / \mathrm{v})$ formaldehyde and $0.3 \%(\mathrm{w} / \mathrm{v})$ glutaraldehyde and washed twice in the same buffer containing $10 \mathrm{mM}$ glycine. Lowicryl K4M resin was used for embedding the cells (Gerberding \& Mayer, 1988; Roth et al., 1981). Sections were cut with an Ultracut E (Reichert-Jung) ultramicrotome, mounted on nickel grids and kept, face down, on drops of PBS until they were immunolabelled. Gold-conjugates (10 nm) (goat anti-mouse; BBI) at a dilution of 1:100 were used to detect bound primary antibody (polyclonal mouse BfpU antiserum, $1: 10)$. A $4 \%(\mathrm{w} / \mathrm{v})$ aqueous uranyl acetate solution $(\mathrm{pH} 4.8)$ was used for post-staining of the sections.

Cell fractionation. Bacteria were grown under BFP-inducing conditions and centrifuged $\left(4000 \mathrm{~g}, 15 \mathrm{~min}\right.$ at $\left.4{ }^{\circ} \mathrm{C}\right)$. IPTG $(1 \mathrm{mM})$ was added to the cultures for the last hour of incubation to induce $\beta$-galactosidase expression. The supernatants were passed through a $0.2 \mu \mathrm{m}$ filter and concentrated by precipitation with $10 \%(\mathrm{v} / \mathrm{v})$ trichloroacetic acid. The precipitate was resuspended in $1 / 200 \mathrm{vol}$. of SDS loading buffer containing $10 \%$ saturated Tris base. The pellets of the culture were resuspended in 1/200 vol. of TEX buffer $[50 \mathrm{mM}$ Tris $/ \mathrm{HCl}(\mathrm{pH} 8 \cdot 0$ ), $3 \mathrm{mM}$ EDTA, $0 \cdot 1 \%$ (v/v) Triton X-100] and held on ice for $30 \mathrm{~min}$. After centrifugation $(10000 \mathrm{~g}$, $10 \mathrm{~min}$ at $4^{\circ} \mathrm{C}$ ), the supernatant was carefully removed and another volume of TEX buffer was added without resuspending the pellet. The supernatant of a second centrifugation was combined with the first to yield the periplasmic fraction, and the pellet was resuspended in SDS-PAGE loading buffer to yield a volume of the cellular fraction that was equivalent to that of the periplasmic fraction.

Sucrose-floatation density-gradient centrifugation. Sucrosefloatation density-gradient centrifugation was performed as described previously (Anantha et al., 2000).

$\mathrm{N}$-terminal sequencing. Affinity-purified C-terminal hexahistidine-tagged BfpU was electroblotted onto a PVDF membrane, visualized with Sypro Ruby Red Blot Stain (Bio-Rad) and subjected to Edman degradation (Biomolecular Research Facility, University of Virginia).

\section{RESULTS}

\section{A bfpU mutant is deficient in the production of BFP and associated phenotypes}

We engineered a non-polar mutation in $b f p U$ and used allelic exchange to move the mutated allele to the wildtype EPEC background. The mutation consisted of the replacement of the nucleotides encoding amino acids 60-129 of the 157 aa protein with a non-polar aphA-3 cassette encoding kanamycin resistance. This cassette was designed with stop codons in all three reading frames preceding the aphA-3 gene, which is followed by a ribosome-binding site and a start codon to resume translation of the $3^{\prime}$ end of the gene into which it is inserted (Ménard et al., 1993). Thus, the cassette has no effect on transcription and should not perturb downstream translation, as demonstrated previously (Ménard et al., 1993; Anantha et al., 2000). The correct orientation and reading frame of the cassette were confirmed by DNA sequencing. PCR amplification of $b f p U$ from

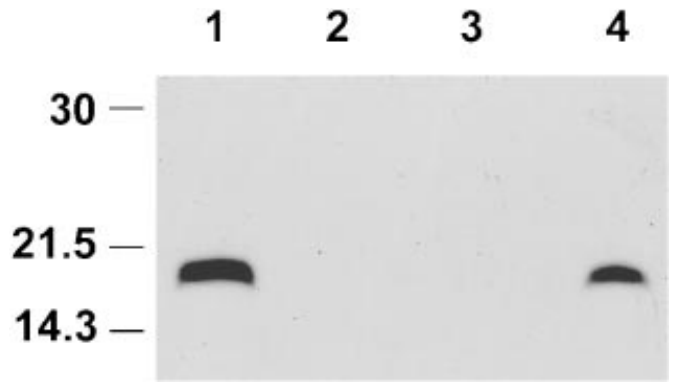

Fig. 2. A bfpU mutant strain does not produce BfpU. Immunoblot of whole-cell lysates from wild-type EPEC strain E2348/69 (lane 1), bfpU mutant strain UMD922 (lane 2), UMD922 transformed with pRPA103 encoding bfpA-U' (lane 3 ) and UMD922 transformed with pMSD233 encoding $b f p A-D^{\prime}$ (lane 4) probed with a mAb against BfpU. The positions of molecular mass markers (in kDa) are indicated on the left.

wild-type strain E2348/69 and mutant strain UMD922 confirmed the predicted $640 \mathrm{bp}$ increase in the size of the product (corresponding to the deletion of $210 \mathrm{bp}$ plus the addition of $a p h A-3)$, while amplification of the nearby $b f p A$ and $b f p I$ genes (see Fig. 1) showed no change in mobility (data not shown). We detected no effect of the mutation on colony morphology or growth.

To detect $\mathrm{BfpU}$, we first constructed a vector encoding a hexahistidine-BfpU fusion protein. We amplified the $b f p U$ gene lacking the nucleotides encoding the putative signal sequence and cloned the PCR product into an expression vector such that the product of the gene fusion would have an amino-terminal hexahistidine tag. We then purified the fusion protein from cell lysates on a nickel/nitriloacetic acid column and used the purified protein to generate a mAb against BfpU. The $b f p U$ mutant, UMD922, no longer produced a protein recognized on immunoblot by the mAb directed at $\mathrm{BfpU}$ (Fig. 2).

Strains that produce BFP exhibit two easily observed phenotypes - the capacity for auto-aggregation and the ability to adhere to tissue-culture cells in clusters (a pattern termed localized adherence). An auto-aggregation index, derived by growing the bacteria under BFP-expressing conditions and calculating the percentage increase in the $\mathrm{OD}_{600}$ value after vortexing in comparison to before vortexing, was used to quantify this phenomenon. Whereas the wild-type auto-aggregation index was $159 \pm 72 \%$ (mean of four determinations \pm SEM), the index for the bfpU mutant was $1 \cdot 8 \pm 1 \cdot 1 \%$. Similarly, whereas the wild-type strain formed large microcolonies on the surface of HEp-2 cells, no such localized adherence was seen with the $b f p U$ mutant (Fig. 3A, C).

We examined cultures of wild-type EPEC bacteria and of the $b f p U$ mutant by transmission electron microscopy after negative-staining. Flexible pili that aggregated into bundles were observed only in the wild-type culture. No 

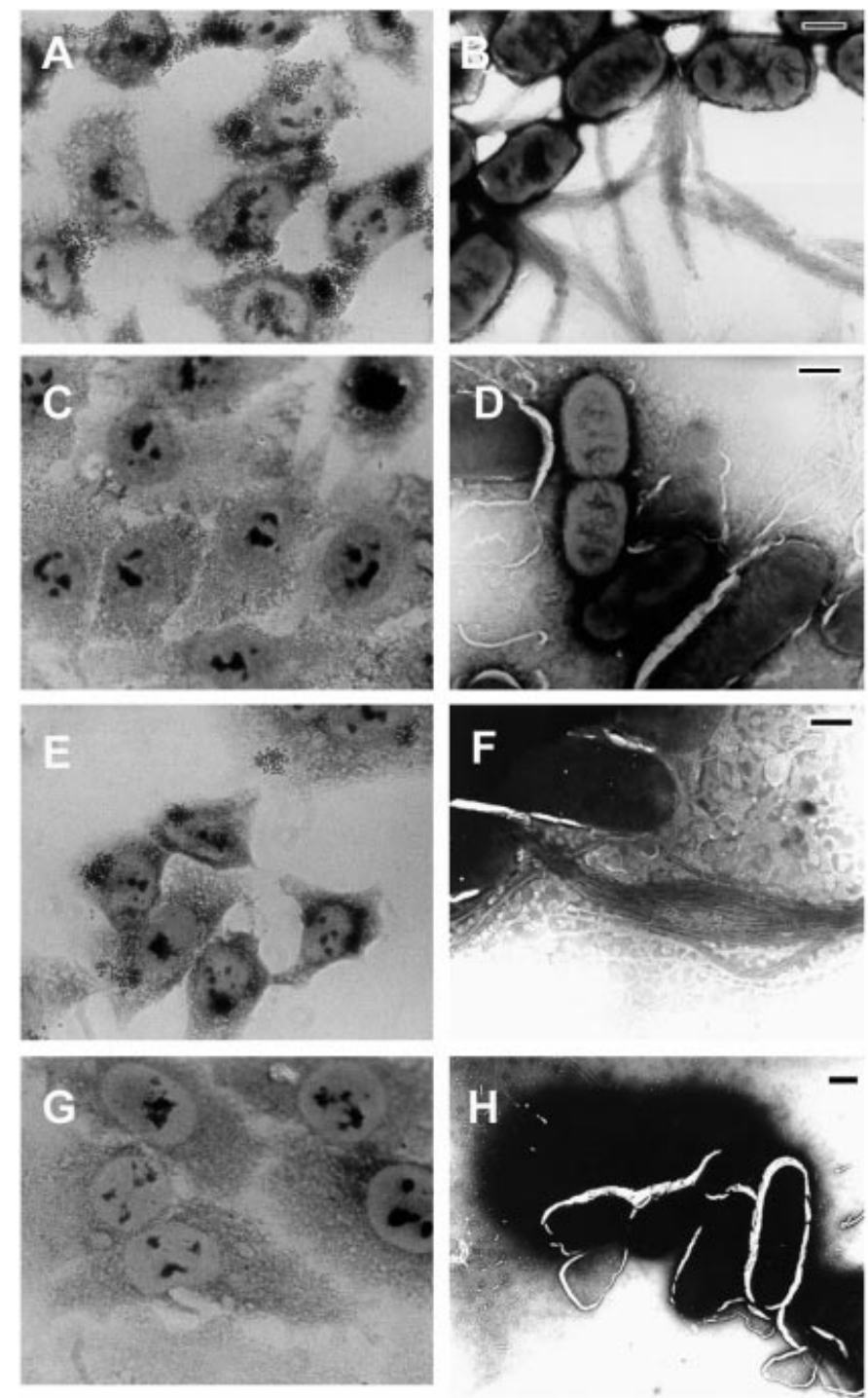

Fig. 3. A $b f p U$ mutant strain is unable to adhere to HEp-2 cells in a localized pattern and does not produce BFP. HEp-2 cells were infected with wild-type EPEC strain E2348/69 (A), bfpU mutant strain UMD922 (C), UMD922 transformed with pMSD233 encoding bfpA-D' (E) and UMD922 transformed with pRPA103 encoding $b f p A-U^{\prime}(G)$. Infected cells were fixed and stained with Giemsa. Cultures of wild-type EPEC strain E2348/69 (B), bfpU mutant strain UMD922 (D), UMD922 transformed with pMSD233 encoding $b f p A-D^{\prime}(F)$ and UMD922 transformed with pRPA103 encoding bfpA- $U^{\prime}(H)$ were stained with phosphotungsten and examined by electron microscopy for the presence of BFP. Bars, $500 \mathrm{~nm}$. pili were seen in the culture of the $b f p U$ mutant (Fig. 3B, D).

\section{Complementation of the bfpU mutant}

To verify that the phenotypes of the $b f p U$ mutant were due to mutation of the $b f p U$ gene, we attempted to complement the mutant with a variety of plasmids containing $b f p U$. We were unable to demonstrate complementation with pMSD232 containing $b f p U$ alone cloned in the low-copy-number vector pWKS30 (data not shown). To better control BfpU expression we attempted to complement the $b f p U$ mutant with pMSD201. This plasmid is a pBR322 derivative containing a BamHI fragment that extends from $273 \mathrm{bp}$ upstream of $b f p A$, which includes the promoter of the bfp operon (Tobe et al., 1996), to include the $5^{\prime}$ end of the sixth gene $(b f p D)$, the locus immediately downstream of $b f p U$ (Fig. 1). Plasmid pMSD201 also failed to complement the mutant (data not shown). However, the same DNA fragment cloned in a lower-copy-number vector (pWKS30) to produce pMSD233 complemented the bfpU mutant to restore BfpU expression (Fig. 2), auto-aggregation $(51 \pm 41 \%)$, localized adherence (Fig. $3 \mathrm{E})$ and morphologically indistinguishable BFP production (Fig. 3F). Note that pMSD233 does not include the entire $b f p D$ locus, and previous studies have demonstrated that it is insufficient to complement a $b f p D$ mutant (Anantha et al., 2000). As a control, we introduced a similar plasmid into the $b f p U$ mutant, except that instead of extending beyond $b f p U$ into the next cistron, this plasmid (pRPA103) contains a BamHI-XbaI fragment that ends within $b f p U$ (Fig. 1). In contrast to pMSD233, pRPA103 failed to restore BfpU expression (Fig. 2) and to complement the mutant for auto-aggregation $(-1 \pm 1 \%)$, localized adherence (Fig. $3 \mathrm{G}$ ) or BFP production (Fig. $3 \mathrm{H}$ ). These results verify that the failure of the $b f p U$ mutant to exhibit localized adherence and to produce BFP is due solely to the mutation in $b f p U$ and not to polar effects on downstream genes. We attribute the absence of complementation by the other plasmids to stoichiometric imbalances, a 


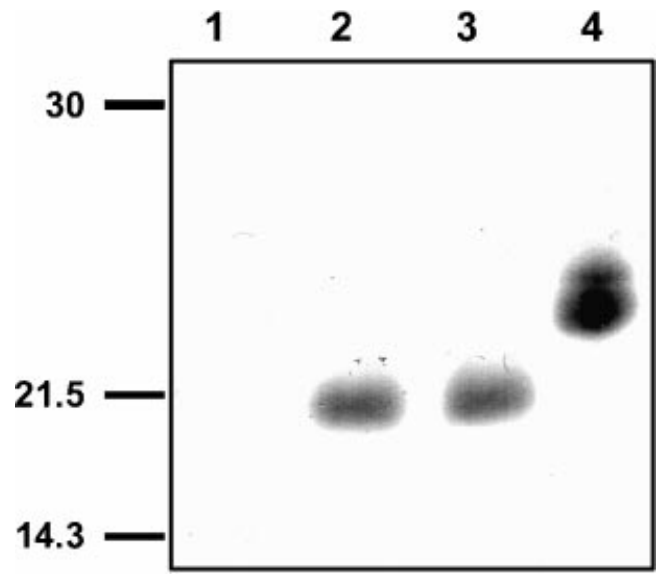

Fig. 4. $B f p U$ is not required for expression or processing of prebundlin. Whole-cell lysates from bfpA mutant strain UMD901 (lane 1), wild-type EPEC strain E2348/69 (lane 2), bfpU mutant strain UMD922 (lane 3 ) and recombinant E. coli strain BL21 (DE3) containing bfpA alone on pMSD205 (lane 4) were separated by SDS-PAGE. Bundlin was revealed by staining with a polyclonal antibody. The positions of molecular mass markers (in $\mathrm{kDa}$ ) are indicated on the left.

problem we have encountered in other mutations within the bfp operon (Anantha et al., 2000).

\section{BfpU does not alter the expression, processing or localization of bundlin in the membrane}

To determine whether the $b f p U$ mutant is capable of expressing pre-bundlin (the BFP pre-pilin encoded by $b f p A)$ and processing the protein to mature bundlin, we performed Western blotting on whole-cell lysates. We found that the $b f p U$ mutant remained capable of expressing and processing pre-bundlin in a manner indistinguishable from that of the wild-type strain (Fig. 4).

The analysis of sucrose-floatation gradients of the wildtype EPEC and $b f p U$ mutant lysates revealed no significant difference in the distribution pattern of bundlin to either the inner or outer membrane (Fig. 5). Thus, the failure of the $b f p U$ mutant strain to produce $\mathrm{BFP}$ is also not attributable to an aberrant sorting of bundlin.

\section{BfpU is a soluble protein partially localized to the periplasm}

As a first step to test the hypothesis that $\mathrm{BfpU}$ is processed by a signal peptidase I, and transported through the inner membrane to the periplasm, we determined the $\mathrm{N}$-terminal sequence of the mature protein. To do this we replaced the $b f p U$ gene in pRPA103 with a PCR fragment encoding BfpU with a Cterminal hexahistidine tag to create pMSD235. This plasmid was able to complement the $b f p U$ mutant for auto-aggregation and localized adherence, indicating that the His tag does not interfere with the function of
BfpU (data not shown). The N-terminal sequence of BfpU-His (EVNTSVDVSGKNDSR), affinity purified from BFP-expressing cultures, was in perfect agreement with the predicted signal peptidase I cleavage site after residue 18 .

To determine the localization of $\mathrm{BfpU}$, we analysed the distribution pattern of $\mathrm{BfpU}$ in sucrose-floatation gradients (Fig. 5a) and found that BfpU remained in the high-density fractions that contained soluble and insoluble proteins. To distinguish between these two alternatives, we grew wild-type EPEC strain E2348/69 and mutant strain UMD922 under BFP-inducing conditions and separated the cell lysates into soluble and insoluble fractions by ultracentrifugation. The quality of the separation was confirmed by probing immunoblots against the soluble protein $\beta$-galactosidase and the outermembrane protein intimin. As shown in Fig. 6, BfpU was released entirely into the soluble fraction, indicating its location in the cytoplasm, the periplasm or both of these compartments.

We used a variety of fractionation procedures to investigate the possibility that $\mathrm{BfpU}$ is located in the periplasm. However, we found that standard procedures such as osmotic shock and sphaeroplast formation led to an unacceptable degree of cell lysis. Therefore, a method using Triton X-100 was selected, as it proved to reliably separate periplasmic and cellular fractions (Thorstenson et al., 1997). The purity of each fraction was assessed using antibodies against the periplasmic maltose-binding protein and the cytoplasmic enzyme $\beta$-galactosidase. Under these conditions, BfpU was detected in both the periplasmic and cellular fractions (Fig. 7). We also examined concentrated culture supernatants for BfpU and for the secreted protein EspB as a control. We did not detect any secreted BfpU.

To verify the localization of BfpU using an alternative method, we used immunogold-labelling of ultra-thin sections of slightly plasmolysed wild-type EPEC cells (Fig. 8). Embedding was done at low temperatures to preserve structures and antigenicity. The majority of gold particles were found close to the membranes. Nevertheless, between 25 and $40 \%$ of the label was found in the cytoplasm, confirming the results of the fractionation studies. No labelling was seen in sections prepared from the $b f p U$ mutant. Thus, we conclude that $\mathrm{BfpU}$ is a soluble protein that is distributed to both the periplasm and the cytoplasm.

\section{Calculation of the number of BfpU molecules per cell in comparison to bundlin}

To calculate how many molecules of bundlin and BfpU are present on average per cell, we conducted quantitative immunoblotting of whole-cell lysates (Fig. 9). Using standard curves of the His-tagged proteins, the molecular masses of His-pre-bundlin, His-BfpU, mature bundlin and mature BfpU, and the known quantities of bacterial c.f.u. that contributed to each lane, we were able to calculate that there are approximately $4 \times 10^{5}$ molecules of bundlin and $9 \times 10^{3}$ molecules of BfpU per 
(a)

$\begin{array}{llllllllllllllllllllllll}1 & 2 & 3 & 4 & 5 & 6 & 7 & 8 & 9 & 10 & 11 & 12 & 13 & 14 & 15 & 16 & 17 & 18 & 19 & 20 & 21 & 22 & 23 & 24\end{array}$ Intis
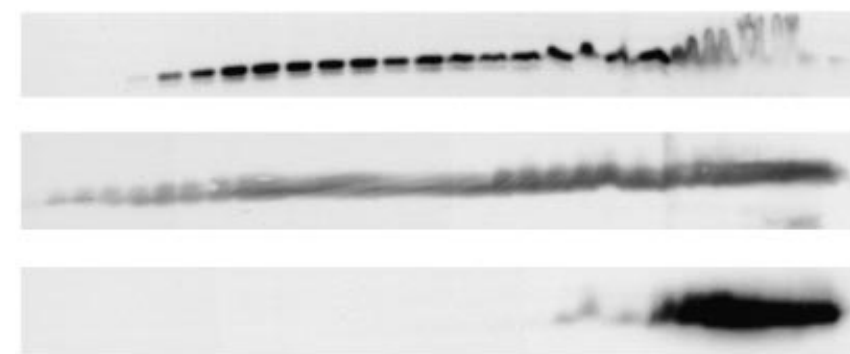

(b)

$\begin{array}{llllllllllllllllllllllll}1 & 2 & 3 & 4 & 5 & 6 & 7 & 8 & 9 & 10 & 11 & 12 & 13 & 14 & 15 & 16 & 17 & 18 & 19 & 20 & 21 & 22 & 23 & 24\end{array}$
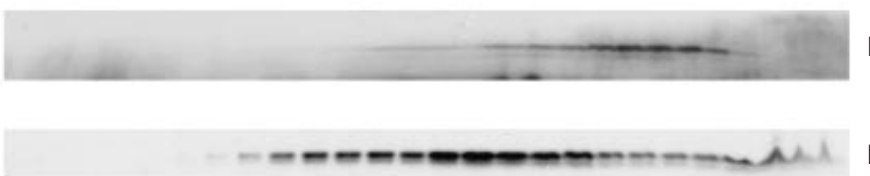

PBPB1

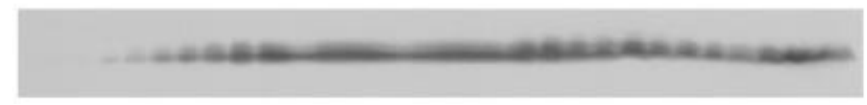

Bundlin
Fig. 5. BfpU does not influence the partitioning of bundlin to both inner and outer membranes. Lysates of the wild-type EPEC strain E2348/69 (a) and the bfpU mutant strain UMD922 (b) were applied to the bottom of a $32-60 \%$ sucrose gradient and centrifuged at $288000 \mathrm{~g}$ for $72 \mathrm{~h}$. Aliquots removed sequentially from the top of the gradient were precipitated and separated by SDS-PAGE, transferred to PVDF membranes and probed with antibodies against the outer-membrane protein intimin and $\mathrm{BfpU}$ as indicated. The blots were then stripped and probed with antibodies against penicillin-binding protein B1 (PBPB1) and bundlin. The lane numbers represent fractions of increasing density from 1.12 to $1.28 \mathrm{~g} \mathrm{ml}^{-1}$. Soluble and insoluble nonmembrane proteins were present in fractions $21-24$ of both gels, as revealed by Ponceau S staining.

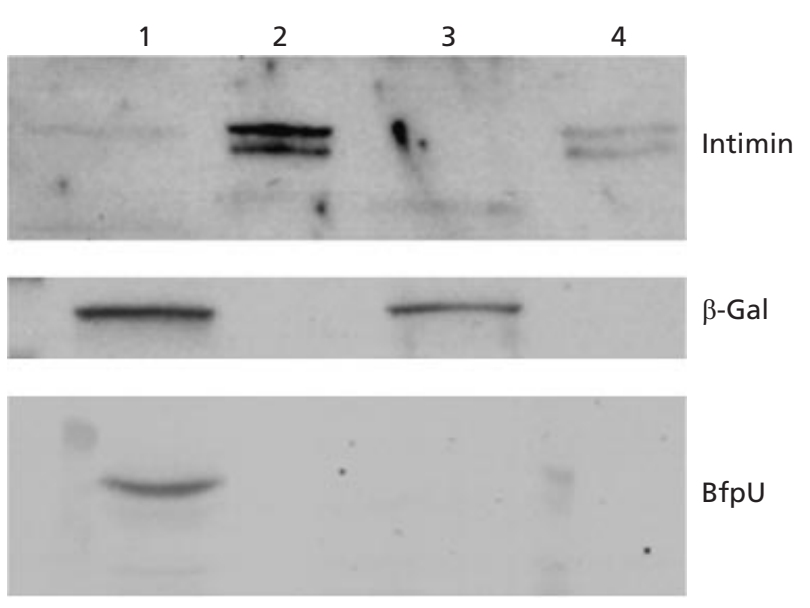

Fig. 6. BfpU does not sediment with membrane proteins after high-speed centrifugation. Western-blot analysis was performed on soluble (lanes 1 and 3 ) and membrane fractions (lanes 2 and 4) of wild-type EPEC strain E2348/69 (lanes 1 and 2) and UMD922 mutant strain (lanes 3 and 4) grown under inducing conditions in DMEM. Equal percentages of the total protein of each fraction were analysed. Antibodies against the soluble protein $\beta$-galactosidase $(\beta$-Gal) and the outermembrane protein intimin were used to assess the quality of the separation.

cell. Similar results were obtained in an independent experiment.

\section{DISCUSSION}

The $b f p$ operon consists of 14 genes that are sufficient to direct the synthesis of the BFP type IV pilus of EPEC in a recombinant host (Stone et al., 1996; Sohel et al.,

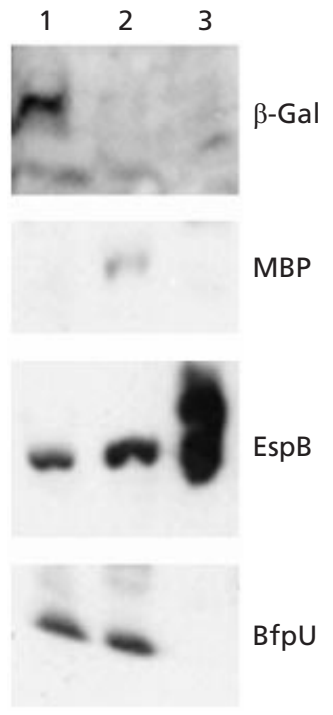

Fig. 7. $B f p U$ is partially extracted with periplasmic proteins. Proteins from cells of wild-type EPEC strain E2348/69 were fractionated by extraction with Triton X-100 into a cellular pellet (lane 1) and an extracted supernatant (lane 2). The culture medium was concentrated by precipitation (lane 3 ). Equivalent volumes of these fractions were separated by SDSPAGE, transferred to PVDF membranes and probed with antibodies against $\beta$-galactosidase $(\beta$-Gal), maltose-binding protein (MBP), EspB and BfpU.

1996). In this report, we have described the initial characterization of $\mathrm{BfpU}$, the fifth protein encoded in this operon. By constructing and complementing a nonpolar $b f p U$ mutant, we have demonstrated that BfpU is 


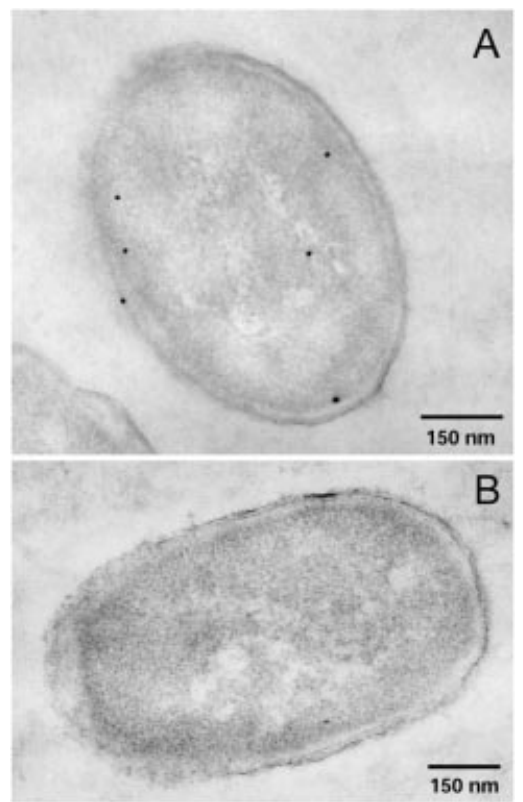

Fig. 8. Immunogold labelling reveals that $B f p U$ is predominantly located near the membranes. BfpU was labelled with polyclonal antiserum followed by labelling with goat-antimouse antibodies conjugated to $10 \mathrm{~nm}$ gold particles. Ultra-thin sections of the wild-type EPEC strain $(A)$ and the bfpU mutant strain (B) are shown.

(a)

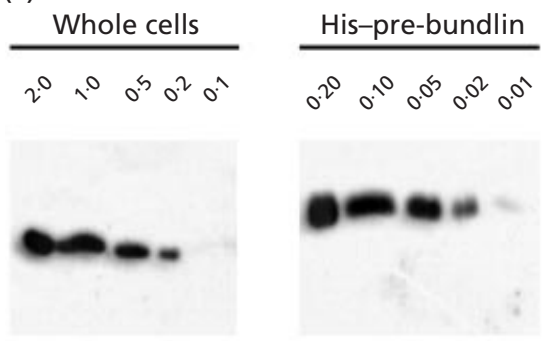

(b)

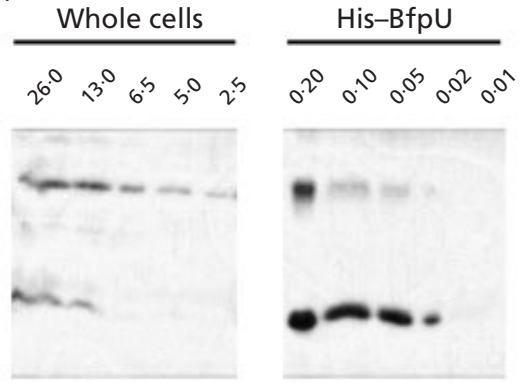

Fig. 9. Proteins from lysates of whole cells, and purified His-pre-bundlin or His-BfpU (as indicated) were separated by SDS-PAGE, transferred to PVDF membranes and probed with mAbs against bundlin (a) or BfpU (b). The amount of protein loaded in the wells (in $\mu \mathrm{g}$ ) is indicated above each lane.

essential for the biogenesis of BFP and for the associated phenotypes of auto-aggregation and localized adher- ence. We have shown that $\mathrm{BfpU}$ is not required for the expression, processing or membrane localization of bundlin, the pilin protein of BFP. We have also shown that $\mathrm{BfpU}$ is a soluble protein and that part of the BfpU pool is localized to the periplasm, as predicted by the amino-acid sequence. The cleavage of the pre-protein at the predicted signal peptidase I cleavage site was confirmed by $\mathrm{N}$-terminal sequencing of the mature protein. Thus, BfpU is the first soluble protein identified that is specifically required for the biogenesis of a type IV pilus. In addition, sucrose-floatation-gradient separation verified that the non-periplasmic pool of $\mathrm{BfpU}$ is not part of the pilus, nor is it localized to the inner or outer membrane. Nevertheless, the fact that successful pilus assembly appears to depend on strict stoichiometric amounts of $\mathrm{BfpU}$ indicates that it might be involved in interactions with components of the pilusassembly machine.

While our experiments do not demonstrate the precise function of BfpU in the biogenesis of BFP, they do shed some light on the process. BfpU appears to have a function that is different from those of other known periplasmic proteins involved in pilus biogenesis. For example, DsbA is a periplasmic protein required for BFP and $\mathrm{P}$ fimbrial biogenesis. In the absence of DsbA, bundlin and the PapD chaperone are unstable and are rapidly degraded (Zhang \& Donnenberg, 1996; JacobDubuisson et al., 1994). However, the absence of BfpU does not lead to bundlin instability nor does it alter the membrane localization of bundlin. Thus, despite its localization in the periplasm, BfpU does not appear to be a specific pilus chaperone, and thus is not analogous to PapD in the P fimbriae system (Lindberg et al., 1989). Instead, our results suggest that $\mathrm{BfpU}$ is part of the machinery necessary either to form pili from pilin monomers or to extrude the pilus structure through the outer membrane. Whether BfpU interacts with the outermembrane protein components BfpB and BfpG (Schmidt et al., 2001) of the BFP assembly apparatus or forms a bridge between inner-membrane proteins such as $\mathrm{BfpE}$ (Blank \& Donnenberg, 2001) and outer-membrane proteins is also amenable to experimental investigation. Nevertheless, these interactions are either very weak or exist only temporarily during the biogenesis process, as no BfpU was detected in the inner- or outer-membrane fractions in sucrose-floatation gradients and no other Bfp proteins co-purify with BfpU. One indication that such interactions may occur is our observation that the cellular abundance of $\mathrm{BfpU}$ is reduced by approximately $75 \%$ in a $b f p B$ mutant strain, suggesting that BfpB may stabilize BfpU (data not shown).

We calculated that there are on average approximately $4 \times 10^{5}$ molecules of bundlin and $9 \times 10^{3}$ molecules of BfpU per EPEC cell when the bacteria are grown under the optimal conditions for BFP expression. This number of bundlin molecules would account for approximately $6.5 \%$ of the total cellular protein. This estimate appears to be accurate, since we calculated that a crude pilus preparation containing $25-50 \%$ bundlin is enriched fivefold for bundlin (data not shown). Thus, there are 
approximately 40 molecules of bundlin for each molecule of $\mathrm{BfpU}$. If one assumes that there is one biogenesis apparatus per pilus (with the pilus protruding through the secretin), and more than 40 bundlin monomers per pilus, this estimate indicates that there is more than one molecule of BfpU per pilus-assembly machine.

It is not yet clear whether the results we report herein extend to other type IV pilus systems. No proteins with primary amino-acid sequences similar to that of BfpU have been described in other pilus biogenesis or related systems. Although the Vibrio cholerae TcpH, TcpQ and TcpS proteins are all similar in size to $\mathrm{BfpU}$, and like $\mathrm{BfpU}$ they contain signal peptidase I leader sequences and have been proposed to be periplasmic (Iredell \& Manning, 1994), these proteins share no significant sequence similarities with BfpU. Similarly, the PilM protein from the R64 thin (type IV) pilus (Kim \& Komano, 1997) and CofG from CFA/III of enterotoxigenic E. coli (Taniguchi et al., 2001) are predicted to be periplasmic proteins of roughly the same size as $\mathrm{BfpU}$, but without sequence similarities. It has been established that PilM is necessary for R64 thin pilus biogenesis (Yoshida et al., 1999), but it remains to be determined whether any of these proteins is a functional homologue of BfpU. Interestingly, the R64 thin pilus, CFA/III and TCP are the three type IV pilus systems most closely related to the BFP system (Spangenberg et al., 1997; Kim $\&$ Komano, 1997). In each of these so-called class B type IV pilus systems the genes are arranged in a tandem cluster, the pilin proteins contain long leader peptides and the amino-terminal residue of the mature pilin is not phenylalanine. Despite these similarities, we found that the BFP apparatus is not capable of assembling TCP (McNamara \& Donnenberg, 2000). It is tempting to speculate that the differences between BfpU and the putative periplasmic TCP proteins could be related to specificity in pilus assembly. The fact that similar periplasmic proteins have not been identified in the class A type IV pilus systems could reflect differences in the mechanisms of pilus biogenesis of these classes. Alternatively, our ignorance of such proteins in class A type IV systems could simply reflect the fact that the genes responsible for type IV pilus biogenesis in these systems are not clustered and have yet to be fully catalogued.

\section{ACKNOWLEDGEMENTS}

We thank Karen Jarvis and James Kaper (both at the Center for Vaccine Development, University of Maryland, Baltimore, MD, USA) for providing pUC18K2, Nanne Nanninga for providing the antibody against penicillin-binding protein $1 \mathrm{~B}$, and Hailang Zhang for technical assistance. This work was supported by Public Health Service award AI37606 from the National Institutes of Health.

\section{REFERENCES}

Alm, R. A. \& Mattick, J. S. (1995). Identification of a gene, pilV, required for type 4 fimbrial biogenesis in Pseudomonas aerugi- nosa, whose product possesses a pre-pilin-like leader sequence. Mol Microbiol 16, 485-496.

Alm, R. A. \& Mattick, J. S. (1997). Genes involved in the biogenesis and function of type-4 fimbriae in Pseudomonas aeruginosa. Gene 192, 89-98.

Alm, R. A., Bodero, A. J., Free, P. D. \& Mattick, J. S. (1996a). Identification of a novel gene, pilZ, essential for type 4 fimbrial biogenesis in Pseudomonas aeruginosa. J Bacteriol 178, 46-53.

Alm, R. A., Hallinan, J. P., Watson, A. A. \& Mattick, J. S. (1996b). Fimbrial biogenesis genes of Pseudomonas aeruginosa: pilW and pilX increase the similarity of type 4 fimbriae to the GSP proteinsecretion systems and pilY1 encodes a gonococcal PilC homologue. Mol Microbiol 22, 161-173.

Anantha, R. P., Stone, K. D. \& Donnenberg, M. S. (1998). Role of $\mathrm{BfpF}$, a member of the PilT family of putative nucleotide-binding proteins, in type IV pilus biogenesis and in interactions between enteropathogenic Escherichia coli and host cells. Infect Immun 66, 122-131.

Anantha, R. P., Stone, K. D. \& Donnenberg, M. S. (2000). Effects of $b f p$ mutations on biogenesis of functional enteropathogenic Escherichia coli type IV pili. J Bacteriol 182, 2498-2506.

Bitter, W., Koster, M., Latijnhouwers, M., de Cock, H. \& Tommassen, J. (1998). Formation of oligomeric rings by XcpQ and PilQ, which are involved in protein transport across the outer membrane of Pseudomonas aeruginosa. Mol Microbiol 27, 209-219.

Blank, T. E. \& Donnenberg, M. S. (2001). Novel topology of BfpE, a cytoplasmic membrane protein required for type IV fimbrial biogenesis in enteropathogenic Escherichia coli. J Bacteriol 183, 4435-4450.

Blank, T. E., Zhong, H., Bell, A. L., Whittam, T. S. \& Donnenberg, M. S. (2000). Molecular variation among type IV pilin $(b f p A)$ genes from diverse enteropathogenic Escherichia coli strains. Infect Immun 68, 7028-7038.

Castric, P. (1995). pilO, a gene required for glycosylation of Pseudomonas aeruginosa 1244 pilin. Microbiology 141, 12471254.

Donnenberg, M. S. \& Kaper, J. B. (1991). Construction of an eae deletion mutant of enteropathogenic Escherichia coli by using a positive-selection suicide vector. Infect Immun 59, 4310-4317.

Donnenberg, M. S. \& Nataro, J. P. (1995). Methods for studying adhesion of diarrheagenic Escherichia coli. Methods Enzymol 253, 324-336.

Donnenberg, M. S., Girón, J. A., Nataro, J. P. \& Kaper, J. B. (1992). A plasmid-encoded type IV fimbrial gene of enteropathogenic Escherichia coli associated with localized adherence. Mol Microbiol 6, 3427-3437.

Donnenberg, M. S., Yu, J. \& Kaper, J. B. (1993). A second chromosomal gene necessary for intimate attachment of enteropathogenic Escherichia coli to epithelial cells. J Bacteriol 175, 4670-4680.

Forest, K. T., Dunham, S. A., Koomey, M. \& Tainer, J. A. (1999). Crystallographic structure reveals phosphorylated pilin from Neisseria: phosphoserine sites modify type IV pilus surface chemistry and fibre morphology. Mol Microbiol 31, 743-752.

Fussenegger, M., Rudel, T., Barten, R., Ryll, R. \& Meyer, T. F. (1997). Transformation competence and type-4 pilus biogenesis in Neisseria gonorrhoeae - a review. Gene 192, 125-134.

Gerberding, H. \& Mayer, F. (1988). Localization of the membranebound hydrogenase in Alcaligenes eutrophus by electron microscopic immunocytochemistry. FEMS Microbiol Lett 50, 265-270. Girón, J. A., Qadri, F., Azim, T., Jarvis, K. J., Kaper, J. B. \& Albert, 
M. J. (1995). Monoclonal antibodies specific for the bundleforming pilus of enteropathogenic Escherichia coli. Infect Immun 63, 4949-4952.

Hobbs, M. \& Mattick, J. S. (1993). Common components in the assembly of type 4 fimbriae, DNA transfer systems, filamentous phage and protein-secretion apparatus: a general system for the formation of surface-associated protein complexes. Mol Microbiol 10, 233-243.

Iredell, J. R. \& Manning, P. A. (1994). The toxin-co-regulated pilus of Vibrio cholerae O1: a model for type 4 pilus biogenesis? Trends Microbiol 2, 187-192.

Jacob-Dubuisson, F., Pinkner, J., Xu, Z., Striker, R., Padmanhaban, A. \& Hultgren, S. J. (1994). PapD chaperone function in pilus biogenesis depends on oxidant and chaperone-like activities of DsbA. Proc Natl Acad Sci U S A 91, 11552-11556.

Jerse, A. E. \& Kaper, J. B. (1991). The eae gene of enteropathogenic Escherichia coli encodes a 94-kilodalton membrane protein, the expression of which is influenced by the EAF plasmid. Infect Immun 59, 4302-4309.

Kim, S. R. \& Komano, T. (1997). The plasmid R64 thin pilus identified as a type IV pilus. J Bacteriol 179, 3594-3603.

LaPointe, C. F. \& Taylor, R. K. (2000). The type 4 prepilin peptidases comprise a novel family of aspartic acid proteases. $J$ Biol Chem 275, 1502-1510.

Levine, M. M., Bergquist, E. J., Nalin, D. R., Waterman, D. H., Hornick, R. B., Young, C. R., Sotman, S. \& Rowe, B. (1978). Escherichia coli strains that cause diarrhoea but do not produce heat-labile or heat-stable enterotoxins and are non-invasive. Lancet 1, 1119-1122.

Levine, M. M., Nataro, J. P., Karch, H., Baldini, M. M., Kaper, J. B., Black, R. E., Clements, M. L. \& O'Brien, A. D. (1985). The diarrheal response of humans to some classic serotypes of enteropathogenic Escherichia coli is dependent on a plasmid encoding an enteroadhesiveness factor. J Infect Dis 152, 550-559.

Lindberg, F., Tennent, J. M., Hultgren, S. J., Lund, B. \& Normark, S. (1989). PapD, a periplasmic transport protein in P-pilus biogenesis. J Bacteriol 171, 6052-6058.

McNamara, B. P. \& Donnenberg, M. S. (2000). Evidence for specificity in type 4 pilus biogenesis by enteropathogenic Escherichia coli. Microbiology 146, 719-729.

Ménard, R., Sansonetti, P. J. \& Parsot, C. (1993). Nonpolar mutagenesis of the ipa genes defines IpaB, IpaC, and IpaD as effectors of Shigella flexneri entry into epithelial cells. J Bacteriol 175, 5899-5906.

Merz, A. J., So, M. \& Sheetz, M. P. (2000). Pilus retraction powers bacterial twitching motility. Nature 407, 98-102.

Nouwen, N., Ranson, N., Saibil, H., Wolpensinger, B., Engel, A., Ghazi, A. \& Pugsley, A. P. (1999). Secretin PulD: association with pilot PulS, structure, and ion-conducting channel formation. Proc Natl Acad Sci U S A 96, 8173-8177.

Nouwen, N., Stahlberg, H., Pugsley, A. P. \& Engel, A. (2000). Domain structure of secretin PulD revealed by limited proteolysis and electron microscopy. EMBO J 19, 2229-2236.

Nunn, D., Bergman, S. \& Lory, S. (1990). Products of three accessory genes, $p i l B$, pilC, and pilD, are required for biogenesis of Pseudomonas aeruginosa pili. J Bacteriol 172, 2911-2919.

Paranchych, W. \& Frost, L. S. (1988). The physiology and biochemistry of pili. Adv Microb Physiol 29, 53-114.

Parge, H. E., Forest, K. T., Hickey, M. J., Christensen, D. A., Getzoff, E. D. \& Tainer, J. A. (1995). Structure of the fibre-forming protein pilin at $2 \cdot 6 \AA$ resolution. Nature 378, 32-38.
Pugsley, A. P. (1993). The complete general secretory pathway in gram-negative bacteria. Microbiol Rev 57, 50-108.

Roth, J., Bendayan, M., Carlemalm, E., Villiger, W. \& Garavito, M. (1981). Enhancement of structural preservation and immunocytochemical staining in low temperature embedded pancreatic tissue. J Histochem Cytochem 29, 663-671.

Russel, M. (1998). Macromolecular assembly and secretion across the bacterial cell envelope: type II protein secretion systems. $J$ Mol Biol 279, 485-499.

Schmidt, S. A., Bieber, D., Ramer, S. W., Hwang, J., Wu, C. Y. \& Schoolnik, G. (2001). Structure-function analysis of BfpB, a secretin-like protein encoded by the bundle-forming-pilus operon of enteropathogenic Escherichia coli. J Bacteriol 183, 4848-4859.

Sohel, I., Puente, J. L., Ramer, S. W., Bieber, D., Wu, C.-Y. \& Schoolnik, G. K. (1996). Enteropathogenic Escherichia coli: identification of a gene cluster coding for bundle-forming pilus morphogenesis. J Bacteriol 178, 2613-2628.

Spangenberg, C., Fislage, R., Römling, U. \& Tümmler, B. (1997). Disrespectful type IV pilins. Mol Microbiol 25, 203-204.

Stimson, E., Virji, M., Makepeace, K. \& 9 other authors (1995). Meningococcal pilin: a glycoprotein substituted with digalactosyl 2,4-diacetamido-2,4,6-trideoxyhexose. Mol Microbiol 17, 12011214.

Stone, K. D., Zhang, H.-Z., Carlson, L. K. \& Donnenberg, M. S. (1996). A cluster of fourteen genes from enteropathogenic Escherichia coli is sufficient for biogenesis of a type IV pilus. Mol Microbiol 20, 325-337.

Strom, M. S., Nunn, D. N. \& Lory, S. (1993). A single bifunctional enzyme, PilD, catalyzes cleavage and $\mathrm{N}$-methylation of proteins belonging to the type IV pilin family. Proc Natl Acad Sci U S A 90, 2404-2408.

Taniguchi, T., Akeda, Y., Haba, A., Yasuda, Y., Yamamoto, K., Honda, T. \& Tochikubo, K. (2001). Gene cluster for assembly of pilus colonization factor antigen III of enterotoxigenic Escherichia coli. Infect Immun 69, 5864-5873.

Thorstenson, Y. R., Zhang, Y., Olson, P. S. \& Mascarenhas, D. (1997). Leaderless polypeptides efficiently extracted from whole cells by osmotic shock. J Bacteriol 179, 5333-5339.

Tobe, T., Schoolnik, G. K., Sohel, I., Bustamante, V. H. \& Puente, J. L. (1996). Cloning and characterization of $b f p T V W$, genes required for the transcriptional activation of $b f p A$ in enteropathogenic Escherichia coli. Mol Microbiol 21, 963-975.

Towbin, H., Staehelin, T. \& Gordon, J. (1979). Electrophoretic transfer of proteins from polyacrylamide gels to nitrocellulose sheets: procedure and some applications. Proc Natl Acad Sci US A 76, 4350-4354.

Virji, M., Saunders, J. R., Sims, G., Makepeace, K., Maskell, D. \& Ferguson, D. J. P. (1993). Pilus-facilitated adherence of Neisseria meningitidis to human epithelial and endothelial cells: modulation of adherence phenotype occurs concurrently with changes in primary amino acid sequence and the glycosylation status of pilin. Mol Microbiol 10, 1013-1028.

Wang, R. F. \& Kushner, S. R. (1991). Construction of versatile lowcopy-number vectors for cloning, sequencing and gene expression in Escherichia coli. Gene 100, 195-199.

Wolfgang, M., Lauer, P., Park, H. S., Brossay, L., Hébert, J. \& Koomey, M. (1998). PilT mutations lead to simultaneous defects in competence for natural transformation and twitching motility in piliated Neisseria gonorrhoeae. Mol Microbiol 29, 321-330.

Wolfgang, M., van Putten, J. P., Hayes, S. F., Dorward, D. \& 
Koomey, M. (2000). Components and dynamics of fiber formation define a ubiquitous biogenesis pathway for bacterial pili. EMBO J 19, 6408-6418.

Yoshida, T., Kim, S. R. \& Komano, T. (1999). Twelve pil genes are required for biogenesis of the R64 thin pilus. J Bacteriol 181, 2038-2043.
Zhang, H.-Z. \& Donnenberg, M. S. (1996). DsbA is required for stability of the type IV pilin of enteropathogenic Escherichia coli. Mol Microbiol 21, 787-797.

Received 4 March 2002; revised 4 April 2002; accepted 19 April 2002. 